ARTICLE OPEN

\title{
Utilization of chemical stability diagrams for improved understanding of electrochemical systems: evolution of solution chemistry towards equilibrium
}

\author{
R. J. Santucci Jr. (D) , M. E. McMahon (D) ${ }^{1}$ and J. R. Scully (iD)
}

Predicting the stability of chemical compounds as a function of solution chemistry is crucial towards understanding the electrochemical characteristics of materials in real-world applications. There are several commonly considered factors that affect the stability of a chemical compound, such as metal ion concentration, mixtures of ion concentrations, pH, buffering agents, complexation agents, and temperature. Chemical stability diagrams graphically describe the relative stabilities of chemical compounds, ions, and complexes of a single element as a function of bulk solution chemistry ( $\mathrm{pH}$ and metal ion concentration) and also describe how solution chemistry changes upon the thermodynamically driven dissolution of a species into solution as the system progresses towards equilibrium. Herein, we set forth a framework for constructing chemical stability diagrams, as well as their application to $\mathrm{Mg}$-based and $\mathrm{Mg}-\mathrm{Zn}$-based protective coatings and lightweight $\mathrm{Mg}$ - $\mathrm{Li}$ alloys. These systems are analyzed to demonstrate the effects of solution chemistry, alloy composition, and environmental conditions on the stability of chemical compounds pertinent to chemical protection. New expressions and procedures are developed for predicting the final thermodynamic equilibrium between dissolved metal ions, protons, hydroxyl ions and their oxides/hydroxides for metal-based aqueous systems, including those involving more than one element. The effect of initial solution chemistry, buffering agents, complexation agents, and binary alloy composition on the final equilibrium state of a dissolving system are described by mathematical expressions developed here. This work establishes a foundation for developing and using chemical stability diagrams for experimental design, data interpretation, and material development in corroding systems.

npj Materials Degradation (2018)2:1 ; doi:10.1038/s41529-017-0021-2

\section{INTRODUCTION}

Corrosion, catalysis, batteries, fuels cells, electrosynthesis, and high temperature oxidation are all areas of chemical science and technology that make use of various diagrams that summarize and map out chemical/electrochemical equilibria as a function of electrode potential, $\mathrm{pH}$, temperature, pressure, etc. Chemical speciation diagrams track the fractional amount of various species of a certain component (such as $\mathrm{H}_{2} \mathrm{CO}_{3}, \mathrm{HCO}_{3}{ }^{-}, \mathrm{CO}_{3}{ }^{2-}$ ) as a function of $\mathrm{pH}$ for a specified component concentration. ${ }^{1-3}$ Phase diagrams depict the dominantly stable equilibrium metallic or intermetallic phase (in the solid or liquid state) as a function of temperature and constituent composition. ${ }^{4}$ In high temperature/ dry oxidation, the Ellingham diagram maps the enthalpy of formation of an oxide comprised of metallic elements as a function of temperature for reactions between the metal and various gaseous phases $\left(\mathrm{O}_{2}, \mathrm{CO}_{2}, \mathrm{H}_{2} \mathrm{O}\right)$ at equilibrium. ${ }^{5}$ The concentration of various types of defects in these oxides can be plotted as a function of the $\mathrm{O}_{2}$ partial pressure with a Brouwer (or Kröger-Vink) diagram. In electrochemistry, the E-pH diagram describes the phase stability of various metals, their dissolved cations or anions, and metallic compounds as a function of $\mathrm{pH}$, electrode potential, and species concentration. ${ }^{6,7}$ This E-pH diagram has been extended to applications, such as nanocluster materials, high temperature conditions, species complexation, and surface science. ${ }^{7-11}$ These equilibrium diagrams have all been employed to predict the thermodynamic feasibility of various reactions and the stability of reaction products as a function of key variables of concern.

Another related and highly complementary diagram, which was published alongside the E-pH diagram for many of the elements in Pourbaix's E-pH Atlas, ${ }^{6}$ is largely under-utilized. This diagram, which was unnamed in the Pourbaix Atlas, will be referred to here as the chemical stability diagram (Fig. 1). It is a graphical representation of the chemical stability of various metallic (or otherwise) compounds principally formed with $\mathrm{OH}^{-}$but possibly also with a host of aqueous species $\left(\mathrm{Cl}^{-}, \mathrm{CO}_{3}{ }^{2-}, \mathrm{PO}_{4}{ }^{3-}\right.$, etc) as a function of $\mathrm{pH}$ and aqueous metal ion concentration, $\left[\mathrm{M}^{n+}\right]{ }^{6}$

The electrochemical behavior of a material is often governed by $\mathrm{pH}$, metal ion concentration, formation of surface oxides and hydroxides, etc., all of which are schematically represented by and analyzed in the chemical stability diagram for specific material systems.

The goal of this work is to demonstrate the invaluable utility of chemical stability diagrams (which predict the stability of corrosion reaction products) towards enhancing the understanding of many engineering-relevant electrochemical systems where the compounds formed depend on ionic content and $\mathrm{pH}$. We demonstrate the derivation and use of chemical stability diagrams

\footnotetext{
'Department of Materials Science and Engineering, Center for Electrochemical Science and Engineering, School of Engineering and Applied Science at the University of Virginia, Charlottesville, VA 22904, USA

Correspondence: R. J. Santucci Jr. (rjs4dv@virginia.edu)
}

Received: 1 September 2017 Revised: 1 November 2017 Accepted: 6 November 2017

Published online: 09 January 2018 


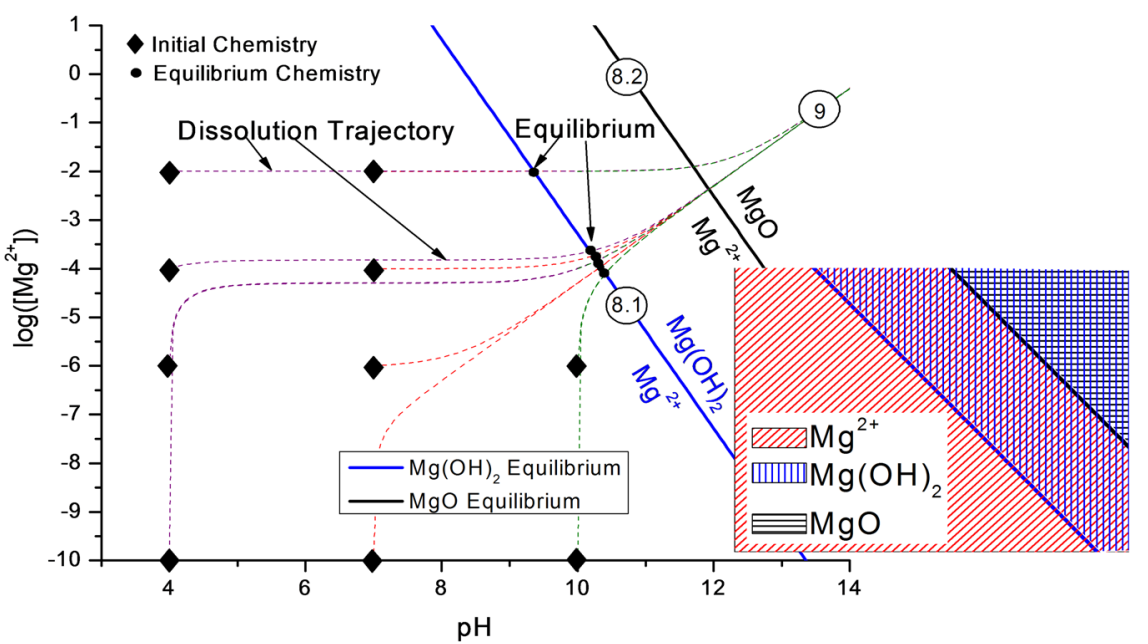

Fig. 1 Chemical stability diagram depicting the relative stabilities of $\mathrm{Mg}^{2+}, \mathrm{Mg}(\mathrm{OH})_{2}$, and $\mathrm{MgO}$. The thick solid lines describe the equilibrium condition for $\mathrm{Mg}(\mathrm{OH})_{2}$ (blue, line 8.1) and $\mathrm{MgO}$ (black, Line 8.2) formation. Thin dashed lines describe the trajectory by which the solution chemistry changes from an initial condition ( $\bullet$ ) to an equilibrium condition $(\bullet)$ as $\mathrm{Mg}, \mathrm{Mg}(\mathrm{OH})_{2}$, or $\mathrm{MgO}$ dissolves into solution (line 9). Each trajectory line corresponds to a different initial solution chemistry for various $\left[\mathrm{Mg}^{2+}\right]$ at $\mathrm{pH} 4$ (purple), 7 (red), and 10 (green). Included is an inset graph which depicts the $\mathrm{pH}$ and $\left[\mathrm{Mg}^{2+}\right]$ conditions of predominance for $\mathrm{Mg}^{2+}, \mathrm{Mg}(\mathrm{OH})_{2}$, and $\mathrm{MgO}$ in $\mathrm{pH}-\left[\mathrm{Mg}^{2+}\right] \mathrm{space}$

here by highlighting three metal-electrolyte systems in which the chemical stability diagram can be utilized to elucidate a deeper understanding of the chemistry pertinent to corrosion behavior in innovative, yet radically different material systems. These analyses also serve to inform unexplained results in these case studies, as well as to supplement previously reported results with farreaching, application-relevant stability predictions. Furthermore, new developments in the methods for chemical stability diagram construction and formulation are reported.

This work demonstrates the powerful analysis which can be performed by a chemical stability diagram framework, especially when deployed in tandem with existing thermodynamic diagram frameworks (such as speciation diagrams, E-pH diagrams, and phase diagrams). The use of these diagrams broadens the methods with which to analyze observations and behaviors in chemical, electrochemical, and geological applications.

\section{RESULTS AND DISCUSSION}

Case study I-solution chemistry evolution of an alloyed electrode: $\mathrm{Mg}-\mathrm{Zn}$ pigments for metal rich coatings

Sacrificial anode-based cathodic protection is commonly employed for corrosion prevention in structural materials. ${ }^{3,12-28}$ Some proven systems employed for this purpose include $\mathrm{Zn}$ based coatings for steel and Mg-based and Al-based coatings for aluminum alloys. ${ }^{3,14-16,18-29}$ All of these systems function primarily by galvanic coupling of the anodic metal pigments to another material in order to suppress corrosion degradation. The performance of the galvanic couple is influenced by $\mathrm{pH}$, metal ion concentration, pigment passivation, pigment composition, and ionic strength. ${ }^{23,26}$ These factors are considered in utilization of the chemical stability diagram, which predicts final equilibrium solution chemistry.

$\mathrm{Mg}-\mathrm{Zn}$ alloyed pigments have been developed in an effort to combine the beneficial corrosion product formation associated with $\mathrm{Zn}^{2+}$ cations with the greater galvanic protection potential driving force of the $\mathrm{Mg}$ metal (i.e., larger OCP difference). 2,18,30-34 The work by Plagemann et al. will be used here to exemplify the utility of chemical stability diagrams. ${ }^{18}$ Most notably, a thermodynamic framework is needed to explain the observed disparity in corrosion product (unidentified) formation as a function of different $\mathrm{Mg}-\mathrm{Zn}$ pigment compositions exposed to constant salt spray exposure testing. ${ }^{18}$

$M g-Z n$ stability diagram development. Chemical stability diagrams for $\mathrm{Mg}-\mathrm{Zn}$ alloy pigments on an aluminum alloy substrate can be used to ascertain how the condition of solution chemistry known here as the chemical solution trajectory $\left(\left[\mathrm{M}^{n+}\right]\right.$ and $\left.\mathrm{pH}\right)$ is affected when the dissolving material produces various ratios of $M_{\mathrm{A}}{ }^{n+}$ and $M_{\mathrm{B}}{ }^{n+}$. The anodic charge produced during metallic oxidation at the $\mathrm{Mg} / \mathrm{Zn}$ pigment is balanced by cathodic charge from mainly the hydrogen evolution reaction and to a lesser extent oxygen reduction reaction. For dissolution of the alloyed pigment, the anodic charge will be divided between $\mathrm{Mg}$ and $\mathrm{Zn}$. This division alters their individual chemical trajectories from the case of either pure $M_{\mathrm{A}}$ or $M_{\mathrm{B}}$. As a first order approximation, it was assumed here that congruent dissolution occurred such that the anodic charge was distributed between $\mathrm{Mg}$ and $\mathrm{Zn}$ atoms according to the atomic fraction of each within the alloy. Assuming open-circuit congruent dissolution of $\mathrm{Mg}$ and $\mathrm{Zn}, \mathrm{a}$ new expression was developed which more generally describes the $\left[\mathrm{Mg}^{2+}\right]$ and $\mathrm{pH}$ trajectory for any alloy composition (see Supplementary Methods Section 2 for more details), given in Eq. 1.

$$
\begin{aligned}
\log \left[\mathrm{Mg}^{2+}\right]=\log ( & {\left[\mathrm{Mg}^{2+}\right]_{\text {init }}+\frac{X}{n}\left[\left(10^{-\mathrm{pH}_{\text {init }}}-10^{-\mathrm{pH}_{\text {inst }}}\right)\right] } \\
& \left.+\frac{X}{n}\left[10^{\mathrm{pH}_{\text {inst }}-14}-10^{\mathrm{pH}_{\text {init }}-14}\right]\right)
\end{aligned}
$$

where $x$ is the atomic fraction of $M g$ in the $M g-Z n$ alloy and $n$ is the charge of the ion under consideration. A similar expression for the $\mathrm{Zn}$ chemical trajectory can be derived where $x$ is replaced by $1-x$, and $\left[\mathrm{Mg}^{2+}\right]$ is replaced by $\left[\mathrm{Zn}^{2+}\right]$. Figure 2 graphically represents the effect of alloy composition on $M_{A}{ }^{n+}$ and $M_{B}{ }^{n+}$ concentrations $\left(\left[\mathrm{M}^{n+}\right] / \mathrm{pH}\right.$ chemical trajectory). Through congruent dissolution, the lower the $\mathrm{Mg}$ content of the alloy, the less $\mathrm{Mg}^{2+}$ there will be in solution from dissolution. The equilibrium condition for corrosion product formation for each element depends on the thermodynamic stability of the ions and compounds considered, which vary for each element and for different compounds. Consider the case of $\mathrm{ZnO}$ and $\mathrm{Mg}(\mathrm{OH})_{2}$ stability in initially low $\left[\mathrm{Zn}^{2+}\right]$ and $\left[\mathrm{Mg}^{2+}\right]$ at $\mathrm{pH} 7$ (Fig. 2). Much less $\mathrm{Zn}^{2+}$ production and alkalinization is required in order for $\mathrm{Zn}^{2+}$ to reach equilibrium with $\mathrm{ZnO}\left(\mathrm{pH}=8.49,\left[\mathrm{Zn}^{2+}\right]=1.55 \times 10^{-6} \mathrm{M}\right)$ 


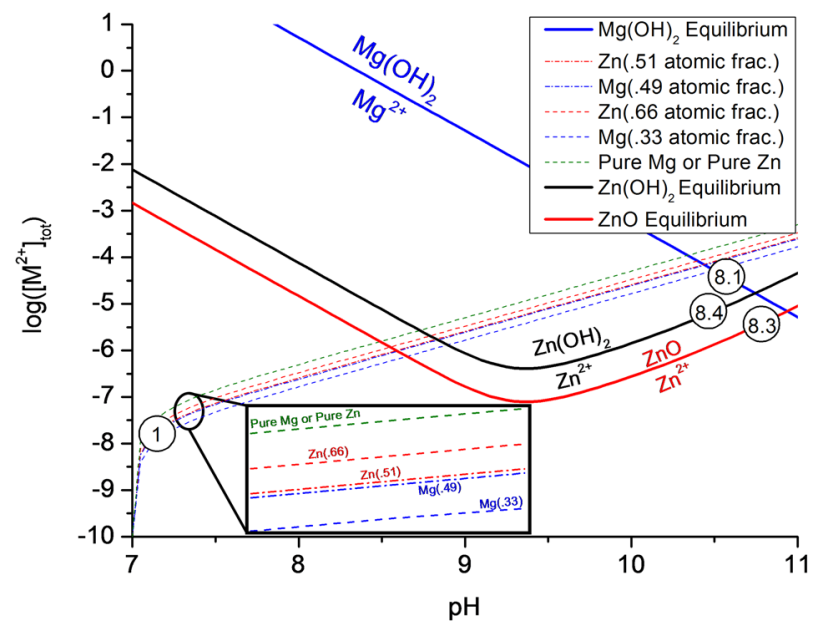

Fig. 2 Chemical stability diagram depicting the relative stabilities/ equilibrium conditions (thick solid lines) of $\mathrm{Mg}(\mathrm{OH})_{2}$ (blue, line 8.1), $\mathrm{ZnO}$ (red, line 8.3), and $\mathrm{Zn}(\mathrm{OH})_{2}$ (black, line 8.4) as a function of $\mathrm{pH}$ and $\left[\mathrm{M}^{2+}\right]$. Included are trajectory lines (thin dashed/dotted lines) for various $\mathrm{Mg}-\mathrm{Zn}$ pigments dissolving towards the $M^{n+} / \mathrm{MX}$ equilibrium conditions (line 1, for various $\mathrm{Mg}-\mathrm{Zn}$ ratios). The composition of the $\mathrm{Mg}-\mathrm{Zn}$ pigment affects the trajectory of the evolving solution chemistry. An inset is included which shows this effect in more detail for various $M g(x)-Z n(1-x)$ alloy compositions

compared to the concentration of $\mathrm{Mg}^{2+}$ required to reach equilibrium with $\mathrm{Mg}(\mathrm{OH})_{2}\left(\mathrm{pH}=10.34,\left[\mathrm{Mg}^{2+}\right]=1.09 \times 10^{-4} \mathrm{M}\right)$. At the point where the solution is saturated with $\mathrm{Zn}^{2+}$, any additional oxidation of $\mathrm{Zn}$ to $\mathrm{Zn}^{2+}$ will result in supersaturation and then formation of more $\mathrm{ZnO}$ by consuming $\mathrm{Zn}^{2+}$ and $\mathrm{OH}^{-}$ions, resulting in no net change in the solution chemistry (hence, equilibrium condition).

The disparity in $\mathrm{ZnO}$ and $\mathrm{Mg}(\mathrm{OH})_{2}$ stability has consequences on the progression of the $\mathrm{Mg}-\mathrm{Zn}$ system towards equilibrium. Even after $\mathrm{ZnO}$ equilibrium has been reached, there is still a driving force to supply $\mathrm{Mg}^{2+}$ and increase $\mathrm{pH}$ towards $\mathrm{Mg}(\mathrm{OH})_{2}$ equilibrium. The $\mathrm{Mg}^{2+}$ and $\mathrm{Zn}^{2+}$ chemistry will cooperatively evolve until $\mathrm{Mg}^{2+}$ and $\mathrm{Zn}^{2+}$ are both in equilibrium with their respective stable compounds. It is assumed that $\mathrm{Mg}$ and $\mathrm{Zn}$ do not form a coordinated mixed compound and the presence of either ion does not change the equilibrium of the other ion's corrosion product. These scenarios could be considered elsewhere. Once $\mathrm{Zn}^{2+}$ reaches equilibrium (assumed in this case to be with respect to $\mathrm{ZnO}$ ), it remains in the equilibrium state and any change in $\mathrm{pH}$ is caused by additional $\mathrm{Mg}^{2+}$ supply via electrochemical dissolution. Therefore, a new trajectory expression for $\mathrm{Mg}$ dissolution must be derived in which $\mathrm{Mg}^{2+}$ dissolution occurs to increase $\left[\mathrm{M}^{n+}\right]$ and $\mathrm{pH}$, moving the system towards $\mathrm{Mg}^{2+}$ equilibrium with $\mathrm{Mg}(\mathrm{OH})_{2}$, while simultaneously satisfying the already achieved $\mathrm{Zn}^{2}$ + equilibrium with ZnO (see Supplementary Methods Section 3 for more details). Equation 2 describes this new trajectory for $\mathrm{Mg}^{2+}$.

$$
\begin{aligned}
& \log \left[\mathrm{Mg}^{2+}\right]=\log ([\left.\mathrm{Mg}^{2+}\right]_{\text {init }}+1\left[\left(10^{-\mathrm{pH}_{\text {init }}}-10^{\left.\left.-\mathrm{pH}_{\text {inst }}\right)\right]}\right.\right. \\
&\left.+1\left[10^{\mathrm{pH}_{\text {inst }}-14}-10^{\mathrm{pH}_{\text {init }}-14}\right]\right)
\end{aligned}
$$

The $\mathrm{Mg}^{2+}-\mathrm{pH}$ condition will follow this new $\mathrm{Mg}^{2+}$ chemical trajectory under the requirement of simultaneously satisfying the $\mathrm{Zn}^{2+}$ equilibrium. The transition from the dissolution described by Eq. 1 and that by Eq. 2 occurs at the $\left[\mathrm{Mg}^{2+}\right]$ and pH at which $\mathrm{Zn}^{2+}$ first reaches equilibrium (dependent upon $\mathrm{Mg}-\mathrm{Zn}$ composition). The final condition of equilibrium occurs where $\mathrm{Mg}^{2+}$ and $\mathrm{Zn}^{2+}$ both coexist at their equilibrium conditions at the same $\mathrm{pH}$ and for

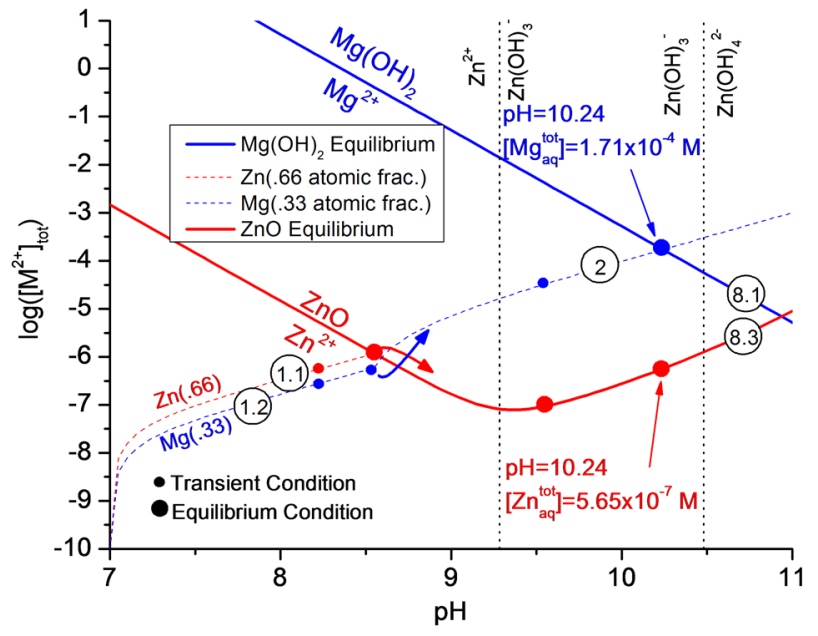

Fig. 3 Chemical stability diagram showing the equilibrium conditions for the most stable corrosion product compounds (thick solid lines) for the $\mathrm{Zn}^{2+} / \mathrm{ZnO}$ (red, line 8.3) and $\mathrm{Mg}^{2+} / \mathrm{Mg}(\mathrm{OH})_{2}$ (blue, line 8.1) systems, respectively. The trajectory lines describing the evolution of solution $\mathrm{pH}$ and metal ion concentration (thin dashed lines) with respect to $\left[\mathrm{Zn}^{2+}\right]$ (red, 1.1) and $\left[\mathrm{Mg}^{2+}\right]$ (blue, 1.2) are shown. The trajectory for $\mathrm{Zn}$ dissolution follows line 1.1 and then the equilibrium boundary for $\mathrm{Zn}^{2+} / \mathrm{ZnO}$ equilibrium line 8.3 upon intersecting it as noted by the red arrow. The Mg chemical trajectory follows the paths indicated; one path prior to the intersection of the $\mathrm{Zn}$ dissolution and equilibrium boundary (line 1.2) and a different path after that intersection (line 2), as noted by the blue arrow. The boundaries between the regions of $\mathrm{pH}$ where different aqueous $\mathrm{Zn}$ based ions are predominantly stable are indicated by thin vertical dotted lines at the $\mathrm{pH}$ value for which the two ions are equal in concentration

their respective equilibrium metal ion concentrations. The full treatment of dissolution and final equilibrium of a Zn.66-Mg.33 alloy in an initial solution at $\mathrm{pH} 7$ with no initial $\mathrm{Mg}^{2+}$ or $\mathrm{Zn}^{2+}$ ions is graphically represented in Fig. 3. This $\mathrm{Mg} / \mathrm{Zn}$ atomic fraction was selected based on the predominance of the $\mathrm{Zn}_{2} \mathrm{Mg}$ intermetallic compound in the $\mathrm{Mg}-\mathrm{Zn}$ alloys, invariant of the bulk alloy atomic fraction.

$M g-Z n$ stability diagram predictions and results. Several useful inferences can be made from the chemical stability diagram treatment derived here. Firstly, the metal with the harshest requirement on equilibrium (highest metal ion concentration and $\mathrm{pH}$ needed to form the equilibrium corrosion product under consideration) dictates the final $\mathrm{pH}$, as it is the last to reach equilibrium. Here, the final $\mathrm{pH}$ of the alloy system is closer to the expected equilibrium $\mathrm{pH}$ for a pure $\mathrm{Mg}$ system than for a pure $\mathrm{Zn}$ system.

Secondly, the composition of the Mg-Zn alloy can be varied to investigate how the final equilibrium solution chemistry will change. The case of pure $\mathrm{Zn}$ or pure $\mathrm{Mg}$ dissolution equilibrium has been discussed in the Methods (Eq. 9). For very dilute compositions of $\mathrm{Mg}$, the trend would progress according to the trajectory established above (Eqs. 1 and 2) but could stop if the system is not able to supply the $\left[\mathrm{Mg}^{2+}\right]$ required for $\mathrm{Mg}(\mathrm{OH})_{2}$ equilibrium due in this case to easy depletion of available $\mathrm{Mg}$ atoms in the pigment. For moderate Mg compositions (such as those presented in the study ${ }^{18}$ ), the final solution chemistry of the $\mathrm{Mg}-\mathrm{Zn}$ system was predicted to be invariant of $\mathrm{Mg}$ or $\mathrm{Zn}$ composition. This is due in part to the relative disparity in $\mathrm{ZnO}$ stability and $\mathrm{Mg}(\mathrm{OH})_{2}$ instability. Any $\mathrm{Mg}^{2+}$ chemical trajectories occurring according to Eq. 2 in cooperation with $\mathrm{Zn}^{2+}$ equilibrium arising from different $\mathrm{Mg}-\mathrm{Zn}$ compositions will simply converge to the same trajectory at high enough $\left[\mathrm{Mg}^{2+}\right]$ and $\mathrm{pH}$ before reaching the $\mathrm{Mg}(\mathrm{OH})_{2}$ equilibrium. This converging effect is 
exemplified clearly in Fig. 1. For this same reason, varying the initial $\mathrm{pH}$ will also not significantly change the final equilibrium conditions of $\mathrm{pH},\left[\mathrm{Mg}^{2+}\right]$, and $\left[\mathrm{Zn}^{2+}\right]$ for reasonable $\mathrm{pH}$ ranges expected for outdoor exposure.

Third, while the final equilibrium condition for $\mathrm{Mg}^{2+}$ and $\mathrm{Zn}^{2+}$ together is expected not to vary significantly with alloy compositions, the $\mathrm{pH}$ and $\left[\mathrm{Zn}^{2+}\right]$ at which $\mathrm{Zn}^{2+}$ first satisfies equilibrium will vary with $\mathrm{Mg} / \mathrm{Zn}$ alloying ratio, again assuming congruent dissolution. Greater $\mathrm{Zn}$ concentrations in the alloy result in the $\mathrm{Zn}^{2+} / \mathrm{ZnO}$ equilibrium being reached at lower $\mathrm{pH}$ values and higher $\left[\mathrm{Zn}^{2+}\right]$. As the system increases $\mathrm{pH}$ to achieve $\mathrm{Mg}^{2+}$ equilibrium with $\mathrm{Mg}(\mathrm{OH})_{2}$ the $\left[\mathrm{Zn}^{2+}\right]$ will be supersaturated and $\mathrm{ZnO}$ will precipitate to decrease $\left[\mathrm{Zn}^{2+}\right]$ to maintain $\mathrm{Zn}^{2+} / \mathrm{ZnO}$ equilibrium. Higher $\mathrm{Zn}$ content alloys will experience the largest decrease in $\left[\mathrm{Zn}^{2+}\right]$ from the concentration of first saturation to the concentration of maximum $\mathrm{ZnO}$ stability as $\mathrm{pH}$ increases towards $\mathrm{Mg}^{2+} / \mathrm{Mg}(\mathrm{OH})_{2}$ equilibrium. This effect is due to the fact that the higher $\mathrm{Zn}$ alloys will first attain $\mathrm{ZnO}$ equilibrium at higher $\left[\mathrm{Zn}^{2+}\right]$. This decrease in $\left[\mathrm{Zn}^{2+}\right]$ is achieved by precipitating $\mathrm{ZnO}$ from solution, which conforms to the experimental finding that higher $\mathrm{Zn}$ content alloys exhibited more corrosion product coverage after exposure. ${ }^{18}$ Overall, these theoretical analyses indicate an optimal $\mathrm{Zn}$ corrosion product production for a $\mathrm{Mg}-\mathrm{Zn}$ composition rich enough with $\mathrm{Zn}$ to intersect $\mathrm{Zn}^{2+}$ equilibrium at high $\left[\mathrm{Zn}^{2+}\right]$ but also with enough $\mathrm{Mg}$ to promote alkalization and further $\mathrm{ZnO}$ production.

The samples highlighted in this case study were subjected to a constant salt spray immersion test ${ }^{18}$ where the exposing electrolyte was constantly replenished to maintain initial solution chemistry. However, corrosion product formation can still occur if the solution becomes stagnant or occluded on the sample surface such that the solution is not replenished. Additionally, in field exposures, wetting and drying cycles introduce periods of stagnation which also play a role in corrosion product formation. Corrosion product formation was hypothesized to play an important role in protecting the substrate during salt spray exposure, ${ }^{18}$ therefore conditions for $\mathrm{ZnO}$ and $\mathrm{Mg}(\mathrm{OH})_{2}$ formation will determine the corrosion product protection capacity of the metal-rich primer system. Several other performance predictions can be derived from these relationships, including the protective pigment capacities of the coating, critical solution volumes, and corrosion product saturation chemistry for any given initial ion content and $\mathrm{pH}$. Specifically, these predictions may be summarized as follows:

1. From the alloyed pigment composition, coating pigment volume concentration, and pigment alloy density, the total moles of $\mathrm{Mg}^{2+}$ and $\mathrm{Zn}^{2+}$ available per area of exposed coating can be determined.

2. From the chemical stability diagrams, the final $\left[\mathrm{Mg}^{2+}\right]$ and $\left[\mathrm{Zn}^{2+}\right]$ required to saturate the solution can be determined, allowing for quantitative evaluation of whether the coating capacity and solution volume allow for equilibrium to be reached.

3. Calculations can be made to determine how much volume of solution is needed for a given area of coating before corrosion product formation is impeded.

4. Given a thin deliquescent film or a spray film volume, the number of wetting and drying cycles required to exceed the ability to achieve $M_{\mathrm{A}}{ }^{n+}$ and $M_{\mathrm{B}}{ }^{n+}$ saturation due to pigment depletion can be determined.

The same procedures outlined here for the $\mathrm{ZnO}$ chemical stability diagram can be applied to chemical stability diagrams constructed for any possible Zn-based corrosion products given the relevant thermodynamic inputs. ${ }^{2,30,32-34}$ Whereas this case study examined the effect of changing the nature of the dissolving interface ${ }^{2,18}$ on the final state of equilibrium, the next section will investigate the effect of changing the nature of the electrolyte on final chemical equilibrium.
Case study II-solution chemistry effects on final equilibrium: Mgrich primer (MgRP) in two different electrolytes

The initial solution chemistry of an electrolyte can have an effect on the trajectory and final equilibrium of an evolving system, as discussed in the Methods and as shown in Fig. 1. A recent study evaluated the performance of a MgRP on 2024 in two different electrolyte solution chemistries. ${ }^{3}$ One solution ( $1 \mathrm{wt} \% \mathrm{NaCl}$ ) is representative of common laboratory solution exposures, while the other solution (dilute Harrison solution, DHS of a given composition) is meant to simulate an outdoor atmospheric solution exposure. DHS is slightly more acidic than the $1 \mathrm{wt} \%$ $\mathrm{NaCl}$ solution and also contains $\mathrm{NH}_{4}{ }^{+}$and $\mathrm{SO}_{4}{ }^{2-}$ ions, which influence the $\mathrm{pH}$ and the formation of $\mathrm{Mg}$-derivative products, as noted by the authors. ${ }^{3}$ It was found that exposure in DHS resulted in a lower final solution $\mathrm{pH}$ and greater depletion of the $\mathrm{Mg}$ pigment from the coating. ${ }^{3}$ Chemical stability diagrams will be used here to quantitatively describe and predict the evolution and final equilibrium solution chemistry for both of these solutions. Specifically, a customized chemical stability diagram will help explain observations made in the case study with regards to pigment depletion and $\mathrm{pH}$ evolution in different electrolyte solutions and will show how the effects are explained by thermodynamic principles.

Mg stability diagram development. The issue with varying electrolyte chemistry is determining how the chemistry of a complex solution affects the chemical trajectory and final equilibrium of a corroding metal surface. Complicating chemical effects need not be considered for the $1 \mathrm{wt} \% \mathrm{NaCl}$ solution, as it is a relatively dilute solution of ions that do not complex strongly with $\mathrm{Mg}^{2+3}$. In contrast, the $\mathrm{pH}$ buffering effects of the DHS must be considered in detail, as $\mathrm{NH}_{4}{ }^{+}$and $\mathrm{SO}_{4}{ }^{2-}$ both participate in proton exchange reactions as dictated by their thermodynamic equilibrium. For each chemical, the proportion of various protonated species can be calculated as a function of $\mathrm{pH}$ (see Supplementary Methods Section 4 for more details). An expression has been derived here (see Supplementary Methods Section 4) which incorporates the $\mathrm{pH}$ buffering effect of the ammonium ion into the $\mathrm{Mg}^{2+}$ chemical trajectory as a function of the overall concentration of $\mathrm{NH}_{3} / \mathrm{NH}_{4}{ }^{+}$in solution $\left(\left[\mathrm{NH}_{4}{ }^{+}\right]_{\text {overall }}\right)$ (Eq. 3).

$$
\begin{aligned}
& \log \left[\mathrm{Mg}^{2+}\right]= \log \left(\frac{1}{n}\left[\mathrm{NH}_{4}^{+}\right]_{\text {overall }}\left\{\frac{\frac{\mathrm{Ka}_{1}}{10^{-\mathrm{pH}}}}{\frac{K \mathrm{~K}_{\text {inst }}}{10^{-\mathrm{pH}} \mathrm{H}_{\text {inst }}}+1}-\frac{\frac{\mathrm{Ka}_{1}}{10^{-\mathrm{pH}}}}{\frac{K \mathrm{~K}_{\text {init }}}{10^{-\mathrm{pH}} \mathrm{PH}_{\text {int }}}+1}\right\}\right. \\
&+\left[\mathrm{Mg}^{2+}\right]_{\text {init }}+\frac{1}{n}\left[\left(10^{-\mathrm{pH}_{\text {init }}}-10^{-\mathrm{pH}_{\text {inst }}}\right)\right] \\
&\left.+\frac{1}{n}\left[10^{\mathrm{pH}_{\text {inst }}-14}-10^{\mathrm{pH}_{\text {init }}-14}\right]\right)
\end{aligned}
$$

Mg stability diagram results and predictions. The different $\mathrm{Mg}^{2+}$ dissolution trends in $1 \mathrm{wt} \% \mathrm{NaCl}$ and DHS are shown in the chemical stability diagram in Fig. 4, where Eq. 3 is plotted as a green line. The buffering effect of the ammonium ion in DHS increased the $\left[\mathrm{Mg}^{2+}\right]$ above that of the unbuffered $1 \mathrm{wt} \% \mathrm{NaCl}$ solution by two orders of magnitude. This results in a lower $\mathrm{pH}$ (9.23) and a higher $\left[\mathrm{Mg}^{2+}\right](.01 \mathrm{M})$ at $\mathrm{Mg}^{2+} / \mathrm{Mg}(\mathrm{OH})_{2}$ equilibrium for MgRP exposed to DHS (Eq. 3). In contrast, exposure in $1 \mathrm{wt} \% \mathrm{NaCl}$ equilibrates at $\mathrm{pH} 10.34$ and $\left[\mathrm{Mg}^{2+}\right]=1.09 \times 10^{-4} \mathrm{M}$ due to the absence of buffering effects (Eq. 9). The final $\mathrm{pH}$ of the $\mathrm{NaCl}$ and the buffered DHS systems as predicted by the mathematical relationship developed here matches well with the experimental results. ${ }^{3}$ It is noted that since the final equilibrium $\left[\mathrm{Mg}^{2+}\right]$ is much higher for the DHS system than the $\mathrm{NaCl}$ system, much more $\mathrm{Mg}$ pigment would need to dissolve into solution before a stable $\mathrm{Mg}(\mathrm{OH})_{2}$ precipitate could form. This follows the experimental 


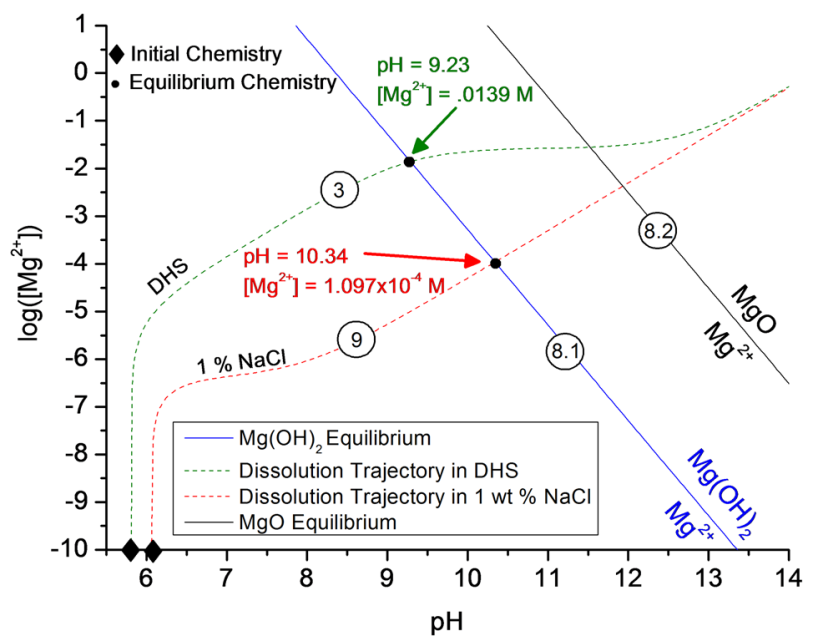

Fig. 4 Chemical stability diagram depicting the effect of initial solution chemistry $(\downarrow)$ on the trajectory and final equilibrium condition (๑) of a corroding $\mathrm{Mg}$ system. It is seen that $\mathrm{Mg}^{2+} / \mathrm{Mg}(\mathrm{OH})_{2}$ equilibrium (line 8.1) is reached under two different conditions. The presence of a pH buffering agent drastically shifts the conditions of final equilibrium as indicated by lines 3 and 9 . Buffering agents have the effect of increasing the amount of metal ion production (line 3 ) required to increase the $\mathrm{pH}$ by the same amount as an unbuffered solution (line 9)

observation that, compared to the $\mathrm{NaCl}$ solution, the DHS system had much more depletion of $\mathrm{Mg}$ pigment in the primer, attributed here to the higher requirement of $\left[\mathrm{Mg}^{2+}\right]$ needed to form $\mathrm{Mg}(\mathrm{OH})_{2}$ in DHS. In contrast, Mg pigment depletion was mitigated in the $\mathrm{NaCl}$ solution and $\mathrm{Mg}(\mathrm{OH})_{2}$ was observed to form on the surface of the Mg pigments. ${ }^{3}$

The question of how the electrolyte chemistry affects the equilibrium conditions for a corroding system has been examined in this module. Following the treatment established here, chemical stability diagrams can be utilized to assess a wide variety of solution effects, such as complexation effects with binding anions and cations, various $\mathrm{pH}$ buffering effects, metal cation buffering effects, solution volume effects, etc. Since the initial solution chemistry of a test electrolyte has been shown to affect the final equilibrium conditions of a corroding system (Figs. 1, 4), it is clear that results depend on experimental details such as consideration of different solution chemistries that exist for different types of laboratory and field exposure..$^{3,33,34}$ For example, differences in solution volume (as with bulk vs. spray vs. thin film vs. droplet exposure), solution composition (as with $\mathrm{NaCl}$ vs. DHS vs. sea water [artificial or otherwise] vs. rain water), and solution aeration (as with deaerated vs. aerated vs. pollutant air) are expected to produce important differences in final equilibrium. Previous research on MgRP has shown that testing in laboratory exposure results in different protection performance with regard to pigment depletion and corrosion product formation as compared to field exposure. ${ }^{24,27,28}$ Field exposure shows variable deposition of $\mathrm{Mg}$ corrosion products in scratches made in the coating with variation in the exposure condition. ${ }^{24,27,28}$ This effect is not unique to MgRP, as similar deposition of $\mathrm{Mg}$ corrosion products into remote scratches has been observed for MgO-rich primers (MgORP). ${ }^{35}$ Though there are differences in the extent of deposition, it is clear that $\mathrm{Mg}^{2+}$ deposition has an important effect on the protection performance of $\mathrm{MgRP}$ and $\mathrm{MgORP},{ }^{35}$ and that the difference between laboratory and field exposure is important. The influence of the exposure environment on material performance will be explored in the next case study.
Case study III-effects of environment on final equilibrium: $\mathrm{Mg}-\mathrm{Li}$ passivating alloys in the presence of carbonate

The formation of a passivating film that prevents significant corrosion damage from occurring is crucial for many corroding systems. For example, a Mg-Li alloy has been developed for aerospace applications that offers spectacular strength-to-weight ratio while also having good atmospheric corrosion resistance, which is attributed to the formation of a passivating $\mathrm{Li}_{2} \mathrm{CO}_{3}$ surface layer. $^{36}$ The specific $\mathrm{Li}$ alloying concentration was designed to stabilize a solid-solution body-centered cubic crystal structure for a Mg-based solid solution instead of the normal hexagonal close-packed crystal structure. ${ }^{36}$ While the Li addition was intended to improve corrosion resistance by promoting a homogenous solid-solution phase, it was also reported to have the unanticipated benefit of forming a Li-based passivating film. ${ }^{36}$ The conditions of stability for this vital passivating film can be explored using chemical stability diagrams.

$M g-L i$ stability diagram development. It is first necessary to determine what compounds should be considered when developing a chemical stability diagram for the Mg-Li alloy system. As is common for outdoor exposure, and as was found in this $\mathrm{Mg}-\mathrm{Li}$ study, carbonate compounds are formed and can be considered along with the usual oxide/hydroxide compounds. 2,24,30,32-34,36-38 The stability of a carbonate compound depends on the concentration of the carbonate ion as a function of $\mathrm{pH}$, as the carbonate ion can participate in proton exchange reactions according to the stability of its variously protonated species as a function of $\mathrm{pH}^{39}$ The total concentration of each carbonate species present as a function of $\mathrm{pH}$ can be calculated as expressed by Eq. 4 for $\mathrm{CO}_{3}{ }^{2-}$.

$$
\left[\mathrm{CO}_{3}^{2-}\right]=\mathrm{C} \times \frac{\frac{4.688 \times 10^{-11}}{10^{-\mathrm{pH}}}}{\frac{10^{-\mathrm{pH}}}{4.446 \times 10^{-7}}+1+\frac{4.688 \times 10^{-11}}{10^{-\mathrm{pH}}}}
$$

Here $C$ is the total concentration of all carbonate species in solution $\left(\mathrm{H}_{2} \mathrm{CO}_{3}+\mathrm{HCO}_{3}{ }^{-}+\mathrm{CO}_{3}{ }^{2-}\right)$, which in turn depends on $\mathrm{pH}$ and the partial pressure of $\mathrm{CO}_{2}$ in the atmosphere. ${ }^{39} \mathrm{~A}$ variety of different total carbonate concentrations can be calculated depending on the conditions of atmospheric exposure. In this treatment, $C$ will be theoretically varied from 1.2 to $1.2 \mathrm{mM}$ in a closed system (for an atmospheric $\mathrm{CO}_{2}$ partial pressure of $4 \times 10^{-4}$ atm, a concentration between $1 \times 10^{-5}$ and $1 \times 10^{-2} \mathrm{M}$ would be reasonable $\left.{ }^{39}\right)$. With this expression for the concentration of $\mathrm{CO}_{3}{ }^{2-}$, an expression for $\left[\mathrm{Li}^{2+}\right]$ in equilibrium with $\mathrm{Li}_{2} \mathrm{CO}_{3}$ as a function of $\mathrm{pH}$ can be derived following the usual procedure, as shown in Eq. 5.

$$
\log \left(\left[\mathrm{Li}^{2+}\right]\right)=-1.544-.5 \log \left(C \times \frac{\frac{4.688 \times 10^{-11}}{10^{-\mathrm{pH}}}}{\frac{10^{-\mathrm{pH}}}{4.446 \times 10^{-7}}+1+\frac{4.688 \times 10^{-11}}{10^{-\mathrm{pH}}}}\right)
$$

The expressions describing the equilibrium for $\mathrm{MgCO}_{3}$, $\mathrm{Mg}(\mathrm{OH})_{2}$, and $\mathrm{Li}_{2} \mathrm{O}$ follow in a similar manner. The chemical trajectories for $\mathrm{Mg}$ and $\mathrm{Li}$ are complicated by the alloyed nature of the $\mathrm{Mg}-\mathrm{Li}$ interface (as with $\mathrm{Mg}-\mathrm{Zn}$ in Case Study I) and the buffering effect of carbonate in solution (as with ammonium in Case Study II). The treatments described in the first two modules focusing on alloyed interfaces and ammonia buffering can also be utilized here to understand the equilibrium corrosion products for a Mg-Li alloy in the presence of carbonate (see Supplementary Methods Section 5 for more details). Application of these treatments enables the derivation of an expression for $\mathrm{Li}^{+}$and $\mathrm{Mg}^{2+}$ chemical trajectory (as shown here for Li in Eq. 6), where $x$ is 
the $\mathrm{Mg}$ composition atomic fraction, $n$ is the number of electrons produced by the oxidation of a single $\mathrm{Li}$ atom, and $K_{\mathrm{a} 1}$ and $K_{\mathrm{a} 2}$ are the equilibrium constants of the two carbonate cycle protonation reactions:

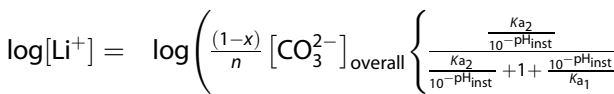

$$
\begin{aligned}
& \left.-\frac{\frac{K \mathrm{a}_{2}}{10^{-P H_{\text {init }}}}}{\frac{K \mathrm{a}_{2}}{10^{-P \mathrm{P}_{\text {init }}}}+1+\frac{10^{-} \mathrm{PH}_{\text {init }}}{K_{\mathrm{a}_{1}}}}\right\}+\left[\mathrm{Li}^{+}\right]_{\text {init }} \\
& +\frac{(1-x)}{n}\left[\left(10^{-p H_{\text {init }}}-10^{-\mathrm{pH}_{\text {inst }}}\right)\right] \\
& \left.+\frac{(1-x)}{n}\left[10^{-\left(14-\mathrm{pH}_{\text {inst }}\right)}-10^{-\left(14-\mathrm{pH}_{\text {init }}\right)}\right]\right)
\end{aligned}
$$

$M g-L i$ stability diagram results and predictions. From Fig. 5, it is immediately evident that the $\mathrm{Li}_{2} \mathrm{CO}_{3}$ and $\mathrm{MgCO}_{3}$ films are most stable at alkaline $\mathrm{pH}$ values (about 10 and higher). Similarly, the carbonate films become more stable as the total concentration of carbonate in solution increases. For example, at a pH of 11 and $\left[\mathrm{CO}_{3}{ }^{2-}\right]$ of $0.0012 \mathrm{M}$, a $\left[\mathrm{Li}^{+}\right]$of $0.89 \mathrm{M}$ is required for $\mathrm{Li}_{2} \mathrm{CO}_{3}$ formation, whereas only a $0.029 \mathrm{M}$ concentration of $\mathrm{Li}^{+}$is needed for a $\left[\mathrm{CO}_{3}{ }^{2-}\right]$ of $1.2 \mathrm{M}$. As previously indicated, ${ }^{36}$ the $\mathrm{Mg}$ and $\mathrm{Li}$ carbonate compounds are more stable than the anhydrous $\mathrm{Mg}$ and $\mathrm{Li}$ oxide compounds over a wide range of $\mathrm{pH}$. This validates the authors' claim that $\mathrm{MgO}$ and $\mathrm{Li}_{2} \mathrm{O}$ would preferentially convert to $\mathrm{MgCO}_{3}$ or $\mathrm{Li}_{2} \mathrm{CO}_{3}$ upon atmospheric exposure to $\mathrm{CO}_{2} \cdot{ }^{36}$ However, these conclusions also suggest that the Mg-Li alloy proposed by these authors is most corrosion resistant for alkaline service conditions ( $>\mathrm{pH} 10$ ) where the carbonate compounds are most stable, which is a noteworthy finding.

It is interesting to note that $\mathrm{MgCO}_{3}$ is thermodynamically stable over a broader range of $\mathrm{pH}$ and $\left[\mathrm{M}^{n+}\right]$ than $\mathrm{Li}_{2} \mathrm{CO}_{3}$ for equivalent carbonate concentrations, even though $\mathrm{Li}_{2} \mathrm{CO}_{3}$ was detected by Xray photoelectron spectroscopy (XPS) and $\mathrm{MgCO}_{3}$ was not. ${ }^{36}$ Additionally, the $\mathrm{Li}_{2} \mathrm{CO}_{3}$ film is much less stable than other classic passivating films such as $\mathrm{Al}_{2} \mathrm{O}_{3}, \mathrm{TiO}, \mathrm{NiO}, \mathrm{FeO}, \mathrm{Cr}_{2} \mathrm{O}_{3}$, etc. which are able to form at $\left[\mathrm{M}^{n+}\right]$ as low as $10^{-10} \mathrm{M}$, compared to $0.1 \mathrm{M}$ for $\mathrm{Li}_{2} \mathrm{CO}_{3}$ (Fig. 5). ${ }^{6}$ This prompts the question of whether or not there might be some other $\mathrm{Li}_{2} \mathrm{CO}_{3}$-derivative compound (such as a lithium carbonate hydrate) which is more stable than either $\mathrm{Li}_{2} \mathrm{CO}_{3}$ or $\mathrm{MgCO}_{3}$. This could explain why a $\mathrm{Li}_{2} \mathrm{CO}_{3}$ peak was detected with XPS instead of an $\mathrm{MgCO}_{3}$ peak. ${ }^{36}$ Alternatively, the authors proposed that the large volume fraction of Li-rich zones in the alloy results in preferential oxidation of Li compared to Mg. ${ }^{36}$ The difference in Nernst potentials of $\mathrm{Li}$ and $\mathrm{Mg}$ may enable more oxidation of $\mathrm{Li}$ compared to $\mathrm{Mg}$, as is commonly seen for alloys comprised of components with substantially different Nernst potentials. ${ }^{6,13,40-42}$

In the case of a congruently corroding binary alloy, the anodic charge was equally distributed between each element according to the composition ratio of the alloy. The procedure developed in Case Study I applicable to congruent dissolution of a corroding $\mathrm{A}-\mathrm{B}$ alloy represented by a given $\left[\mathrm{M}_{\mathrm{A}}{ }^{n+}\right] /\left[\mathrm{M}_{\mathrm{B}}{ }^{n+}\right]$ concentration can be modified to account for concentration differences consistent with dissolution of one element over another. In this case of preferential dissolution, the anodic charge could be distributed in other ways. Additionally, a similar treatment can be used to contrast the ease with which a $\mathrm{Li}_{2} \mathrm{CO}_{3}$ film is able to form on the "Mg-rich" a phase compared to the "Li-rich" $\beta$ phase, as it was suggested that the $\mathrm{Li}_{2} \mathrm{CO}_{3}$ film was able to form on the $\beta$ phase but not the a phase. ${ }^{36}$ It is noted that, should the dominant surface film transition from $\mathrm{Li}_{2} \mathrm{CO}_{3}$ to $\mathrm{MgCO}_{3}$, passivating protection of the alloy may be lost.

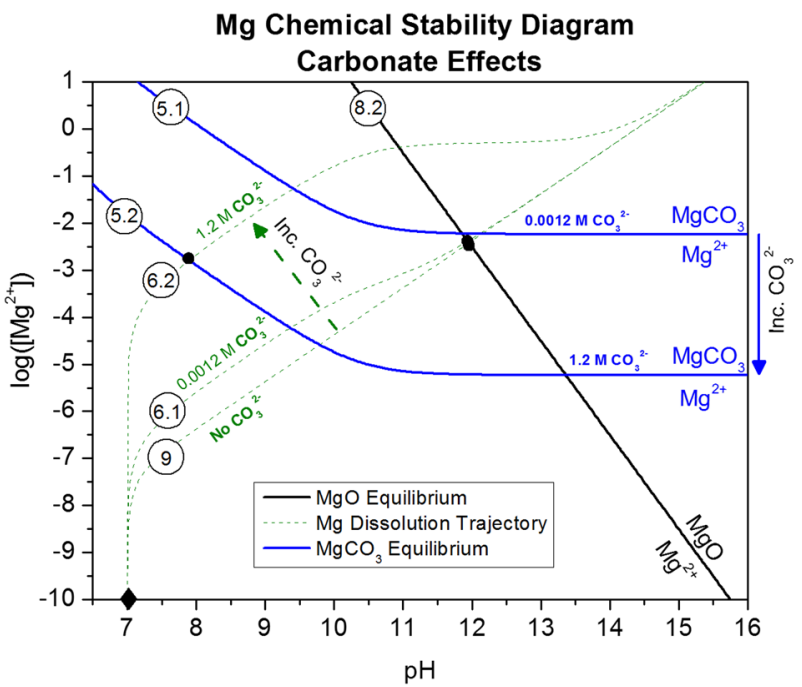

Li Chemical Stability Diagram Carbonate Effects

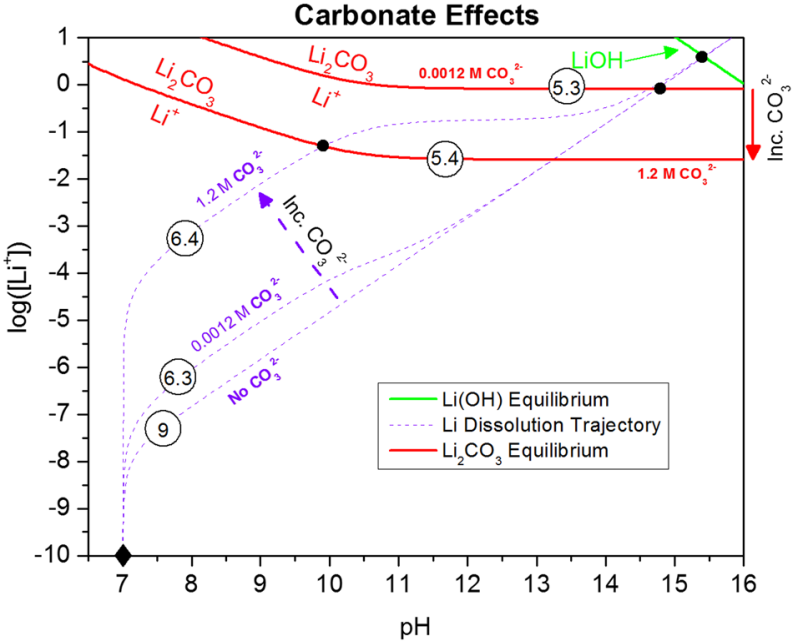

Fig. 5 Chemical stability diagram for the $\mathrm{Mg}$ and Li systems in a closed carbonate-containing electrolyte describing the change in solution chemistry from an initial condition ( $\downarrow$ ) to an equilibrium condition (•). The effect of increasing carbonate concentration in solution on the increasing stability of the $\mathrm{MgCO}_{3}$ (lines 5.1 and 5.2) and $\mathrm{Li}_{2} \mathrm{CO}_{3}$ (lines 5.3 and 5.4) compounds is demonstrated. Also included are the chemical trajectories for $\mathrm{Mg}$ (lines 6.1 and 6.2) and $\mathrm{Li}$ (lines 6.3 and 6.4) considering the alloying composition of the $\mathrm{Mg}-\mathrm{Li}$ alloy and the buffering effect of the carbonate ion

Extended utility of chemical stability diagrams

The approach developed in this analysis finds easy application in several other corrosion and materials engineering challenges facing society at large, especially when properly paired with other existing thermodynamic diagram frameworks. The performance of passivating materials ("stainless" engineering materials) readily depends on the thermodynamic stability of the various oxide films being considered for protection. ${ }^{43-45}$ Likewise, concepts crucial to passivation breakdown such as oxide film dissolution, film destabilization by halide complexation, localized corrosion cells (pits, crevices, thin films, or droplets), and solution acidification via metal ion hydrolysis all find a need for analysis by chemical stability diagrams. ${ }^{43,45-48}$ Some corrosion inhibitor technologies, which rely on the formation of a protective film via chemical storage, release, and subsequent chemical deposition, could benefit greatly from these types of analyses as well. For example, lead pipe water distribution systems are made safer via treatment 
with phosphate inhibitors. ${ }^{49,50}$ Additionally, corrosion protection of aerospace assets was made possible in large part due to the corrosion inhibition afforded by chromium conversion coatings (CCC) ${ }^{51-54}$ With the growing demands for CCC alternatives, other inhibitor solutions (such as, molybdenum and cerium systems) are being heavily researched. $21,22,55-60$ The storage, release, and deposition of these inhibitor species is dependent upon $\mathrm{pH}$, and the critical inhibitor concentration is usually dependent on metal ion concentration in solution. Chemical stability diagrams find application in all of these examples.

Chemical stability diagrams were utilized to explore how various factors affect the final equilibrium condition of corroding electrochemical systems. Diagrams were constructed based on a type of analysis which has existed for many years but which was developed further here for corroding systems. A modified approach was established for predicting the equilibrium conditions for corrosion product formation and how solution chemistry likely evolves during corrosion to achieve this equilibrium in terms of $\mathrm{pH}$ and metal ion concentration, which is applicable to various materials in a variety of testing conditions pertinent to corrosion. Strategies were developed from the chemical stability diagram as follows:

- A mathematical expression was developed which describes the effect of initial $\mathrm{pH}$ and $\left[\mathrm{M}^{n+}\right]$ on the chemical conditions which are anticipated to develop during corrosion. Varying the initial $\mathrm{pH}$ and $\left[\mathrm{M}^{n+}\right]$ of a solution results in different final $\mathrm{pH}$ and $\left[\mathrm{M}^{n+}\right]$ conditions in which equilibrium is established.

- A mathematical expression was developed which describes the $\mathrm{pH}$ and $\left[\mathrm{M}^{n+}\right]$ dissolution-based chemical trajectory of a corroding system as a function of binary alloying composition which could be extended for a larger number of components. The chemical trajectory and final equilibrium of an element is altered from the single-component case when alloys are considered. The final condition of equilibrium for both elements in this case does not vary significantly with modest changes in alloy composition and initial $\mathrm{pH}$.

- A strategy was developed for determining how two different elements are able to evolve towards equilibrium which satisfies the equilibrium conditions for both systems. It was found that the element with the stricter requirement of $\mathrm{pH}$ and $\left[\mathrm{M}^{n+}\right]$ for equilibrium dictated the final solution chemistry.

- A mathematical expression was developed that describes how different $\mathrm{pH}$ buffering species (ammonia and carbonate) alter the chemical trajectory of a corroding system. The presence of a buffering agent requires a greater production of $\left[\mathrm{M}^{n+}\right]$ in order to cause the same change in $\mathrm{pH}$ relative to the evolution of a system in the absence of a buffering agent.

- A mathematical expression was developed which describes the equilibrium $\mathrm{pH}$ and $\left[\mathrm{M}^{n+}\right]$ required for formation of metal carbonate compounds. This expression can be adapted for other $\mathrm{pH}-$ dependent metal-based compounds (carbonates, phosphates, sulfates, etc.). Carbonate compounds are more stable at higher $\mathrm{pH}$ values and may very well be the preferred thermodynamic corrosion product formed in atmospheric exposure.

\section{METHODS}

Construction of the diagrams

As with any phase diagram, expressions must be developed that describe the dependence of free energy on the specific variables of interest. For chemical stability diagrams, conditions of equilibrium must be described as a function of $\mathrm{pH}$, metal ion activity, and temperature (298 K was considered here). Equilibrium boundaries (thick solid lines) between metal ion species and solid metal compounds are constructed from thermodynamic equations that relate the equilibrium stability of various species to $\mathrm{pH}\left(\mathrm{H}^{+} / \mathrm{OH}^{-}\right.$ion concentration) and $\left[\mathrm{M}^{n+}\right]$. Chemical stability diagrams can also depict chemical trajectory paths (thin and long dashed lines) that plot the evolution of metal ion concentration and $\mathrm{pH}$ within a $\log \left[\mathrm{M}^{n+}\right]$ vs. $\mathrm{pH}$ space field as the system progresses from some initial condition to an equilibrium condition. The following generalized procedure was utilized to construct basic equilibrium and trajectory lines for chemical stability diagrams; more advanced treatments are evaluated in the Discussion:

1. Equilibrium boundaries were constructed from relevant chemical potential data for species and compounds under consideration. Lange's Handbook of Chemistry was the source of all thermodynamic data used in this study. ${ }^{61}$ Charge-and-mass-balanced equations were derived to quantify the equilibrium metal ion concentration as a function of $\mathrm{pH}$ (for example, Eq. 7). Examples of compounds that can be considered are oxides, hydroxides, sulfates, and chlorides. These lines can express the equilibrium condition between two aqueous ions or an aqueous ion and a compound (Eq. 8). ${ }^{6}$ Equilibrium boundaries accurately describe the equilibrium condition between two species and are valid for one particular equilibrium reaction condition. By overlaying multiple equilibrium boundaries for various types of metal$\mathrm{X}$ compounds, one can correctly describe a system for any set of solution chemistry conditions with careful consideration. The inherent weakness with any thermodynamic diagram is demonstrated in the case where a set of equilibrium conditions/reactions are not considered when they should be (this is highlighted in Case-Study III).

$a M^{n+}+b \mathrm{H}_{2} \mathrm{O}=M_{\mathrm{a}}(\mathrm{OH})_{\mathrm{b}}+n \mathrm{H}^{+}$

$\log \left[M^{n+}\right]=-\left[\frac{\sum \nu G_{\text {prod }}-\sum \nu G_{\text {reac }}}{2.303 R T}\right]-\frac{n}{a} \mathrm{pH}$

2. Trajectory lines were constructed by deriving balanced expressions to relate the transient metal ion concentration to the concentration of hydroxide or hydronium ions upon dissolution of a solid compound or metal (either chemically or electrochemically; see Supplementary Methods, Section 1). Trajectory lines are often constructed for an initial solution chemistry of $\mathrm{pH} 7$ and minimal $\left[\mathrm{M}^{n+}\right]{ }^{6}$ An expression was derived in this study (see Supplementary Methods, Section 1) which describes the trajectory of a dissolving compound or metal for any starting pH or $\left[\mathrm{M}^{\mathrm{n}}\right]$ (For the example of $\mathrm{Mg}^{2+}$, see Eq. 9). Where $n$ is the number of electrons produced upon oxidation of one $\mathrm{Mg}$ atom, $\left[\mathrm{Mg}^{2+}\right]_{\text {init }}$ is the initial $\mathrm{Mg}^{2+}$ ion concentration (molarity) of the solution, $\mathrm{pH}_{\text {init }}$ is the initial $\mathrm{pH}$ of the solution, and $\mathrm{pH}_{\text {inst }}$ is the instantaneous $\mathrm{pH}$ of the solution as dissolution (and subsequent increase in $\left[\mathrm{OH}^{-}\right]$and $\left[M^{n+}\right]$ ) occurred;

$$
\begin{aligned}
& \log \left[\mathrm{Mg}^{2+}\right]=\log ([\left.\mathrm{Mg}^{2+}\right]_{\text {init }}+\frac{1}{n}\left[\left(10^{-\mathrm{pH}_{\text {init }}}-10^{-\mathrm{pH}_{\text {inst }}}\right)\right] \\
&\left.+\frac{1}{n}\left[10^{\mathrm{pH}_{\text {inst }}-14}-10^{\mathrm{pH}_{\text {init }}-14}\right]\right)
\end{aligned}
$$

Figure 1 graphically represents the relationship described by Eqs. 8 and 9 for a $\mathrm{Mg}^{2+}$ system. The thermodynamic stability fields for $\mathrm{Mg}(\mathrm{OH})_{2}$ and $\mathrm{MgO}$ are depicted as a function of $\mathrm{pH}$ and $\left[\mathrm{Mg}^{2+}\right]$. It is apparent that the final equilibrium condition of a system depends upon the initial solution chemistry, and that the equilibrium Mg-compound produced upon $\mathrm{Mg}(\mathrm{OH})_{2}$ or $\mathrm{MgO}$ dissolution will be $\mathrm{Mg}(\mathrm{OH})_{2}$, as it is far more stable than $\mathrm{MgO}$ in aqueous environments (Fig. 1). The expression derived here provides a quantitative means of understanding how initial conditions affect final conditions with respect to equilibrium $\mathrm{pH},\left[\mathrm{M}^{n+}\right]$, and reaction product formation. Many other situations can alter the conditions for establishment of equilibrium between a metal ion and some stable molecular solid as well as the trajectory of an evolving solution chemistry $\left(\left[\mathrm{M}^{n+}\right], \mathrm{pH}\right)$ upon increase of $\mathrm{M}^{n+}$ and $\mathrm{OH}^{-}$. Three examples were discussed in this manuscript. The equilibrium and trajectory lines in each figure are labelled according to the equation in the manuscript from which they are plotted.

\section{Data availability}

All relevant procedures for constructing the chemical stability diagrams presented here are contained within this publication (and its Supplementary Information files). Relevant thermodynamic values were cited from Lange's Handbook of Chemistry. ${ }^{61}$

Supplementary information is available at Nature Material Degradation's website and contains a List of Terms used in this manuscript (Supplementary Table 1), a breakdown of the chemical trajectory equation 
(Supplementary Note 1), and a list of assumptions and limitations (Supplementary Note 2) for the reader's reference.

\section{ACKNOWLEDGEMENTS}

The authors thank Mr. Jeremy Garritano for his assistance in the collection of thermodynamic data. The authors are grateful for the financial support and contribution of the United States Office of the Undersecretary of Defense Corrosion University Pilot Program FA7000-14-2-0010 under the direction of Mr. Daniel Dunmire, the United States Office of Naval Research N0000141512491 under the direction of Dr. Airan Perez, and the National Science Foundation under NSF DMR \#1309999.

\section{AUTHOR CONTRIBUTIONS}

All authors contributed to the construction of these chemical stability diagrams and to the structure of the manuscript. R.J. Santucci, Jr provided a review of relevant literature for magnesium-based primers and drafted the paper. M.E. McMahon provided a review of relevant literature for zinc-based primers and edited and modified the manuscript. J.R. Scully edited, modified, and reviewed the manuscript and directed the research of this project.

\section{ADDITIONAL INFORMATION}

Supplementary information accompanies the paper on the npj Materials Degradation website (https://doi.org/10.1038/s41529-017-0021-2).

Competing interests: The authors declare that they have no competing financial interests.

Publisher's note: Springer Nature remains neutral with regard to jurisdictional claims in published maps and institutional affiliations.

\section{REFERENCES}

1. Ogle, K., Morel, S. \& Jacquet, D. Observation of Self-healing functions on the cut edge of galvanized steel using SVET and pH Microscopy. J. Electrochem. Soc. 153, B1-B5 (2006).

2. Volovitch, P., Allely, C. \& Ogle, K. Understanding corrosion via corrosion product characterization: I. Case study of the role of $\mathrm{Mg}$ alloying in $\mathrm{Zn}-\mathrm{Mg}$ coating on steel. Corros. Sci. 51, 1251-1262 (2009).

3. Lin, M. J., Battocchi, D. D. \& Bierwagen, P. G. Degradation of magnesium rich primers over AA2024-T3 during constant immersion in different solutions. Corrosion 73, 408-416 (2017).

4. Chang, Y. A. et al. Phase diagram calculation: past, present and future. Prog. Mater. Sci. 49, 313-345 (2004).

5. Ellingham, H. J. T. Transactions and communications. J. Soc. Chem. Ind. 63, 125-160 (1944).

6. Pourbaix, M. Atlas of Electrochemical Equilibria in Aqueous Solutions (National Association of Corrosion Engineers, Houston, Texas, 1974).

7. Huang, L. F., Hutchison, M. J., Santucci, R. J., Scully, J. R. \& Rondinelli, J. M. Improved electrochemical phase diagrams from theory and experiment: the $\mathrm{Ni}-$ water system and its complex compounds. J. Phys. Chem. C 121, 9782-9789 (2017).

8. Beverskog, B. \& Puigdomenech, I. Revised pourbaix diagrams for chromium at 25-300 ${ }^{\circ} \mathrm{C}$. Corros. Sci. 39, 43-57 (1997).

9. Taylor, C. D., Neurock, M. \& Scully, J. R. First-principles investigation of the fundamental corrosion properties of a model Cu38 nanoparticle and the (111), (113) surfaces. J. Electrochem. Soc. 155, C407-C414 (2008).

10. Rojas-Hernández, A., Ramírez, M. T., Ibáñez, J. G. \& González, I. Construction of multicomponent pourbaix diagrams using generalized species. J. Electrochem. Soc. 138, 365-371 (1991).

11. Nila, C. \& González, I. Thermodynamics of $\mathrm{Cu}-\mathrm{H}_{2} \mathrm{SO}_{4}-\mathrm{Cl}-\mathrm{H}_{2} \mathrm{O}$ and $\mathrm{Cu}-\mathrm{NH}_{4} \mathrm{Cl}-\mathrm{H}_{2} \mathrm{O}$ based on predominance-existence diagrams and pourbaix-type diagrams. Hydrometallurgy 42, 63-82 (1996).

12. Francis, R. A. \& Association, A. C. Sixty Years of Inorganic Zinc Coatings: History, Chemistry, Properties, Applications and Alternatives (Australasian Corrosion Association, Mount Waverley, Victoria, 1999).

13. Scully, J., Silverman, D. \& Kendig, M. Electrochemical Impedance: Analysis and Interpretation. (ASTM International, West Conshohocken, Pennsylvania, 1993).

14. Theiler, F. The rust preventing mechanism of zinc dust paints. Corros. Sci. 14, 405-414 (1974).

15. Nightingall, V. C. J. Protectively coated ferrous metal surfaces and method of producing same (United States of America patent, Victoria, Australia, 1948).
16. Kalendová, A., Veselý, D., Kohl, M. \& Stejskal, J. Anticorrosion efficiency of zincfilled epoxy coatings containing conducting polymers and pigments. Prog. Org. Coat. 78, 1-20 (2015).

17. Jr., S. F., Morcillo, M. \& Feliu, S. Deterioration of cathodic protection action of zincrich paint coatings in atmospheric exposure. Corrosion 57, 591-597 (2001).

18. Plagemann, P., Weise, J. \& Zockoll, A. Zinc-magnesium-pigment rich coatings for corrosion protection of aluminum alloys. Prog. Org. Coat. 76, 616-625 (2013).

19. Lin, J., Battocchi, D. \& Bierwagen, G. P. Inhibitors for prolonging corrosion protection of Mg-rich primer on Al alloy 2024-T3. J. Coat. Technol. Res. 14, 497-504 (2017).

20. Scully, J. R., Presuel-Moreno, F., Goldman, M., Kelly, R. G. \& Tailleart, N. Userselectable barrier, sacrificial anode, and active corrosion inhibiting properties of Al-Co-Ce alloys for coating applications. Corrosion 64, 210-229 (2008).

21. Presuel-Moreno, F. J., Goldman, M. E., Kelly, R. G. \& Scully, J. R. Electrochemical sacrificial cathodic prevention provided by an Al-Co-Ce metal coating coupled to AA2024-T3. J. Electrochem. Soc. 152, B302-B310 (2005).

22. Presuel-Moreno, F., Jakab, M. A., Tailleart, N., Goldman, M. \& Scully, J. R. Corrosionresistant metallic coatings. Mater. Today 11, 14-23 (2008).

23. King, A. D., Lee, J. S. \& Scully, J. R. Galvanic couple current and potential distribution between a $\mathrm{Mg}$ electrode and 2024-T351 under droplets analyzed by microelectrode arrays. J. Electrochem. Soc. 162, C12-C23 (2015).

24. Kannan, B. \& Scully, J. R. Performance of a magnesium-rich primer on pretreated AA2024-T351 in selected laboratory and field environments: conversion coating pretreatments. Corrosion 72, 1363-1384 (2016).

25. Nanna, M. \& Bierwagen, G. Mg-rich coatings: a new paradigm for $\mathrm{Cr}$-free corrosion protection of Al aerospace alloys. J. Coat. Technol. Res. 1, 69-80 (2004).

26. King, A. D., Lee, J. S. \& Scully, J. R. Finite element analysis of the galvanic couple current and potential distribution between $\mathrm{Mg}$ and 2024-T351 in a Mg rich primer configuration. J. Electrochem. Soc. 163, C342-C356 (2016).

27. King, A. D., Kannan, B. \& Scully, J. R. Environmental degradation of a Mg-rich primer in selected field and laboratory environments: part 1-without a topcoat. Corrosion 70, 512-535 (2014).

28. King, A. D., Kannan, B. \& Scully, J. R. Environmental degradation of a Mg-rich primer in selected field and laboratory environments: part 2-primer and topcoat. Corrosion 70, 536-557 (2014).

29. King, A. D. \& Scully, J. R. Sacrificial anode-based galvanic and barrier corrosion protection of 2024-T351 by a Mg-rich primer and development of test methods for remaining life assessment. Corrosion 67, 055004-055001-055004-055022 (2011).

30. Duchoslav, J. et al. Evolution of the surface chemistry of hot dip galvanized $\mathrm{Zn}-\mathrm{Mg}-\mathrm{Al}$ and $\mathrm{Zn}$ coatings on steel during short term exposure to sodium chloride containing environments. Corros. Sci. 91, 311-320 (2015).

31. Krieg, R., Rohwerder, M., Evers, S., Schuhmacher, B. \& Schauer-Pass, J. Cathodic self-healing at cut-edges: the effect of $\mathrm{Zn}^{2+}$ and $\mathrm{Mg}^{2+}$ ions. Corros. Sci. 65, 119-127 (2012)

32. Salgueiro Azevedo, M., Allély, C., Ogle, K. \& Volovitch, P. Corrosion mechanisms of $\mathrm{Zn}(\mathrm{Mg}, \mathrm{Al})$ coated steel: 2 . The effect of $\mathrm{Mg}$ and $\mathrm{Al}$ alloying on the formation and properties of corrosion products in different electrolytes. Corros. Sci. 90, 482-490 (2015).

33. Salgueiro Azevedo, M., Allély, C., Ogle, K. \& Volovitch, P. Corrosion mechanisms of $\mathrm{Zn}(\mathrm{Mg}, \mathrm{Al})$ coated steel in accelerated tests and natural exposure: 1. The role of electrolyte composition in the nature of corrosion products and relative corrosion rate. Corros. Sci. 90, 472-481 (2015).

34. Salqueiro Azevedo, M., Allély, C., Ogle, K. \& Volovitch, P. Corrosion mechanisms of $\mathrm{Zn}(\mathrm{Mg}, \mathrm{Al})$ coated steel: the effect of $\mathrm{HCO}^{3-}$ and $\mathrm{NH}^{4+}$ ions on the intrinsic reactivity of the coating. Electrochim. Acta 153, 159-169 (2015).

35. Santucci, M. R., Kannan, M. B., Abbott, D. W. \& Scully, D. J. Magnesium and magnesium oxide primer on 2024-T351: assessment of field performance (under review). Corrosion 73, 1196-1201 (2017).

36. $\mathrm{Xu}, \mathrm{W}$. et al. A high-specific-strength and corrosion-resistant magnesium alloy. Nat. Mater. 14, 1229-1235 (2015).

37. Pathak, S., Blanton, M., Mendon, S. \& Rawlins, J. Mineralogical transformation and electrochemical nature of magnesium-rich primers during natural weathering. Metals 4, 322 (2014).

38. Turel, T., Pathak, S. S., Mendon, S. K., Blanton, M. D. \& Rawlins, J. W. Treatment of $\mathrm{Mg}$ powder with carbonic acid and the effect of treatment variables and treated $\mathrm{Mg}$ ratios on coating performance in salt spray tests. J. Coat. Technol. Res. 10, 475-483 (2013)

39. Persat, A., Chambers, R. D. \& Santiago, J. G. Basic principles of electrolyte chemistry for microfluidic electrokinetics. Part I: Acid-base equilibria and $\mathrm{pH}$ buffers. Lab Chip 9, 2437-2453 (2009).

40. Aburada, T., Fitz-Gerald, J. M. \& Scully, J. R. Pitting and dealloying of solute-rich Al-Cu-Mg-based amorphous alloys: effect of alloying with minor concentrations of nickel. J. Electrochem. Soc. 158, C253-C265 (2011). 
41. Aburada, T., Fitz-Gerald, J. M. \& Scully, J. R. Synthesis of nanoporous copper by dealloying of $\mathrm{Al}-\mathrm{Cu}-\mathrm{Mg}$ amorphous alloys in acidic solution: the effect of nickel. Corros. Sci. 53, 1627-1632 (2011).

42. Lebouil, S., Tardelli, J., Rocca, E., Volovitch, P. \& Ogle, K. Dealloying of Al2Cu, Al7Cu2Fe, and Al2CuMg intermetallic phases to form nanoparticulate copper films. Mater. Corros. 65, 416-424 (2014).

43. Frankel, G. S., Li, T. \& Scully, J. R. Perspective-localized corrosion: passive film breakdown vs pit growth stability. J. Electrochem. Soc. 164, C180-C181 (2017).

44. Lutton, K., Gusieva, K., Ott, N., Birbilis, N. \& Scully, J. R. Understanding multielement alloy passivation in acidic solutions using operando methods. Electrochem. Commun. 80, 44-47 (2017).

45. Newman, R. C. 2001 W.R. Whitney Award Lecture: understanding the corrosion of stainless steel. Corrosion 57, 1030-1041 (2001).

46. Chen, Z. Y. \& Kelly, R. G. Computational modeling of bounding conditions for pit size on stainless steel in atmospheric environments. J. Electrochem. Soc. 157, C69-C78 (2010).

47. Galvele, J. Transport processes in passivity breakdown-II. Full hydrolysis of the metal ions. Corros. Sci. 21, 551-579 (1981).

48. Galvele, J. R. Transport processes and the mechanism of pitting of metals. J. Electrochem. Soc. 123, 464-474 (1976).

49. Boffardi, B. P. \& Sherbondy, A. M. Control of lead corrosion by chemical treatment. Corrosion 47, 966-975 (1991).

50. Ha, H. M. \& Scully, J. R. Effects of phosphate on pit stabilization and propagation in copper in synthetic potable waters. Corrosion 69, 703-718 (2013).

51. llevbare, G. O., Scully, J. R., Yuan, J. \& Kelly, R. G. Inhibition of pitting corrosion on aluminum alloy 2024-T3: effect of soluble chromate additions vs chromate conversion coating. Corrosion 56, 227-242 (2000).

52. Xia, L., Akiyama, E., Frankel, G. \& McCreery, R. Storage and release of soluble hexavalent chromium from chromate conversion coatings equilibrium aspects of Cr VI concentration. J. Electrochem. Soc. 147, 2556-2562 (2000).

53. Xia, L. \& McCreery, R. L. Chemistry of a chromate conversion coating on aluminum alloy AA2024-T3 probed by vibrational spectroscopy. J. Electrochem. Soc. 145, 3083-3089 (1998)

54. llevbare, G. O. \& Scully, J. R. Mass-transport-limited oxygen reduction reaction on AA2024-T3 and selected intermetallic compounds in chromate-containing solutions. Corrosion 57, 134-152 (2001).
55. Jakab, M. A., Presuel-Moreno, F. \& Scully, J. R. Critical concentrations associated with cobalt, cerium, and molybdenum inhibition of AA2024-T3 corrosion: delivery from Al-Co-Ce(-Mo) Alloys. Corrosion 61, 246-263 (2005).

56. Jakab, M. A., Presuel-Moreno, F. \& Scully, J. R. Effect of molybdate, cerium, and cobalt ions on the oxygen reduction reaction on AA2024-T3 and selected intermetallics: experimental and modeling studies. J. Electrochem. Soc. 153 B244-B252 (2006).

57. Jakab, M. A. \& Scully, J. R. On-demand release of corrosion-inhibiting ions from amorphous Al-Co-Ce alloys. Nat. Mater. 4, 667-670 (2005).

58. Jakab, M. A. \& Scully, J. R. Effect of $\mathrm{pH}$ and chloride ion concentration on inhibitor storage in amorphous Al-Co-Ce Alloys. Corrosion 64, 198-209 (2008).

59. Presuel-Moreno, F. J., Jakab, M. A. \& Scully, J. R. Inhibition of the oxygen reduction reaction on copper with cobalt, cerium, and molybdate ions. J. Electrochem. Soc. 152, B376-B387 (2005).

60. Presuel-Moreno, F. J., Wang, H., Jakab, M. A., Kelly, R. G. \& Scully, J. R. Computational modeling of active corrosion inhibitor release from an Al-Co-Ce metallic coating: protection of exposed AA2024-T3. J. Electrochem. Soc. 153, B486-B498 (2006).

61. Dr. James, G. S. in Lange's Handbook of Chemistry, Seventeenth Edition (ed James G. Speight) (McGraw Hill Professional, Access Engineering, New York 2017).

(i) Open Access This article is licensed under a Creative Commons Ay Attribution 4.0 International License, which permits use, sharing, adaptation, distribution and reproduction in any medium or format, as long as you give appropriate credit to the original author(s) and the source, provide a link to the Creative Commons license, and indicate if changes were made. The images or other third party material in this article are included in the article's Creative Commons license, unless indicated otherwise in a credit line to the material. If material is not included in the article's Creative Commons license and your intended use is not permitted by statutory regulation or exceeds the permitted use, you will need to obtain permission directly from the copyright holder. To view a copy of this license, visit http://creativecommons. org/licenses/by/4.0/.

(c) The Author(s) 2018 